\title{
Application of Quality Management System in Tourism Sector in Kosovo
}

\author{
Samir Lleshi, PhD. Cand. \\ Xhenet Syka, PhD. Cand. \\ samir. lleshi@gmail.com
}

\begin{abstract}
Tourism is one of the most complex activities of today's modern society. In developed countries and in some other countries in transition, it presents a significant product of export and employment generator. The increase of the quality of service and application of the quality management system in tourism industry is undoubtedly a challenge that we are all interested to deal with. Quality Management of Services is directly connected with training and qualification of human resources involved in this sector. Tourism sector in recent years, although, it was a priority for each government, we can freely say, it has increased in spontaneous way. More tourists don't mean more progress in development, or generating of incomes for Kosovars. The type of tourism that one country is commited to develop is mainly determined from the contribution for enriching of its inhabitants. Emphasizing of natural and cultural tourism in Kosovo is mainly focused on benefiting from local communities, which, unfortunately, are currently facing the limited economic situation. Positive benefiting from a successful tourism sector strategy directly contributes to increase of employment, additional benefitting for economy, improved infrastructure and increase of tax revenue which directly has an impact in improvement toward health care, education, and other social development.
\end{abstract}

Keywords: QMS, Qualification, Human resorces, Strategy, Education

\section{Introduction}

The concept of quality of tourism services is essential if we want to understand the origin of quality of services and possible gaps in quality. The purpose of this paper is to show the importance of quality management system of hotelier and tourist services from the conceptual point of view of those who are users of these services, so the clients.

Tourism is one of the most complex services in modern society. In developed countries, but also in some countries in transition it is an important export product and employment generator. It includes a wide combination of phenomena and reports arising during the tourist trip, while in its realization is deeply included not only in economic terms but also in terms of ecological, social and cultural life. In Kosovo tourism is an important economic sector. The Kosovo tourism industry has achieved $6-8 \%$ of local social product, depending on the fact what year it was and were there considered all the direct factors (hotel industry, gastronomy) or indirect factors (agriculture, construction, etc. ). These data, however, have only relative value. Greater participation in local social product can only be explained by the weakness of other economic sectors. Greater participation of the tourism economy in local social product reveals, firstly, the weaknesses of other economic sectors and tourism potential as it is not sufficiently utilized. This participation in absolute numbers and the relationship with local social product could be even higher, if the tourist offer advances in quantitative and qualitative terms.

\section{Advantages of touristic company that have implemented QMS ISO 9001}

Through the implementation of the quality management system ISO 9001 the internal functioning in a tourism enterprise becomes more effective and this is reflected through: performance easier to everyday work, reducing the "labor in vain", better use of time, reduction of material consumption, expenditure reserves, better flow of information, other expenditure savings, more efficient monitoring of the overall activities, etc. 
The effects of internal establishing Quality Management System ISO 9001 in enterprises in the tourism sector are realized through: the method of process work organization and management, identification and recognition of clients' requirements, defining the quality policy, quality planning, defining authority and responsibility for certain phases of the work, improving internal communications, surveillance documents, better management of human resources management, more efficient business processes, better organization of supply, but also by monitoring significantly more efficient work and its successes measuring, analyzing the data that lead to continuous improvement, corrective and preventive actions, active improvement and measurement statistics, and effective monitoring of expenditure.

Improving standards of service, so the quality of services and the workforce in the tourism industry, as well as offering consistently appropriate products of value and quality required to meet the needs of target groups, Kosovo can compete successfully in regional markets. Tourism development should be measured and assessed in the medium to long term period, associated with its ability to improve the welfare of Kosovars. In this regard, it can (and should be) a part of the strategy for achieving the country's development priorities. The emphasis on natural and cultural tourism in Kosovo, will maintain focus on benefits for local communities that today are faced with limited economic opportunities. The tangible benefits expected from a successful tourism strategy would be the increased employment, additional income for economies (main or additional), improved infrastructure and increased tax revenues to contribute to improved health care, education and in other social developments.

\section{Results of research carried out in Kosovar touristic industry and discussion}

\section{1 Level of ISO 9001 implementation in Kosovar touristic sectors}

The main issue in many service strategies is quality, which is defined as the main problem for many years. The idea of QMS is well developed after the war in Kosovo by various professional organizations. However, many of the previous works were focused on the product. This is also happening today but not at the same level. Despite this, many companies that offer services even those of tourism sector have realized that quality is essential. Even that they are aware of the need to improve the quality of service, the quality of service remains the main problem still that it is necessary to be solved.

The implementation of QMS in any enterprise or field of tourism involve some requirements that should proceed the start of applying this idea of application for workers and to guide them to achieve the quality objectives effectively; these requirements include (Source: Ishikawa, 1985; Smith 1993):

Reforming the firm culture, learning and training, consultants support, implementation strategy and finally supervision and controlling by correction of any deviations all obstacles that hinder the implementation.

Touristic enterprises perform many activities besides providing and the realization of service. They also perform development, marketing, distribution, warehousing and purchasing. All these activities are process that have to be managed systematically. Therefore, the company should establish, document and implement within its organization a QMS that designed to continually improve its effectiveness (Source: Gilbert, 1992; Ishikawa, 1985)

The first gap can create the quality of service towards customer satisfaction in the tourism industry is knowledge gap. It is the result of the differences that exist in the Management of knowledge and its actual expectations. This gap can lead to other deficiencies in the process of service quality and is caused by: inaccurate information on market research and demand analysis, incorrect interpretation of information about the expectations and the lack of information about any reaction between service providers and customers. (Grzinic, Jasmina, "Concepts of service quality measurement in hotel industry" p. 87,2008$)$

People refer to the human resource base within an organization, which many regard as the most critical in ensuring the success of service sector operations. (Source: Beech, J. , Chadwick, S. (2006), The business of tourism management, Prentice Hall, Harlow)

Implementation of Quality Management System ISO 9001 leads to the increased employee satisfaction of touristic staff (Nield-Kozak 1999, p. 43). 


\section{2 Research and Empirical data}

The research data were collected through questionnaires distributing among tourism enterprises (touristic agency, hotels, restaurants) in Kosovo. Out of the 72 companies for which we had information that have been certified or are in the phase of certification with ISO 9001, 56 fully completed and returned the questionnaire, in this case we will analyze the data for only 6 questions. Each manager of enterprise was given an envelope containing a letter explaining the purpose of the research, the potential benefit of the study. We should mention that these numbers of questionnaires 5 are from hotels. Having analyzed the type of ownership of the touristic enterprises that have implemented or are in the phase of certification ISO 9001 , we have confirmed that we are $100 \%$ private ownership.

In the empirical analysis of this paper, we used the questionnaire data, which are processed in the statistical program SPSS V. 20. In addition we will present the results of descriptive analysis, respectively the cumulative data.

In the question "Do you consider necessarily or obligation to your enterprise to be certified according to the international standard ISO 9001 for QMS" we have the following results:

\section{Chart 1.}

Standard ISO 9001

\begin{tabular}{|l|l|l|l|l|}
\hline & Frequency & Percent & Valid Percent & Cumulative Percent \\
\hline Obligation & 35 & 62.5 & 62.5 & 62.5 \\
Yes & 21 & 37.5 & 37.5 & 100.0 \\
Total & 56 & 100.0 & 100.0 & \\
\hline
\end{tabular}

Source: own construction /calculation SPSS

In the question "Has QMS application requirements positively influenced the implementation of your tasks in your business" we have the following results:

\section{Chart 2.}

Application QMS

\begin{tabular}{|l|l|l|l|l|}
\hline & Frequency & Percent & Valid Percent & Cumulative Percent \\
\hline None & 15 & 26.8 & 26.8 & 26.8 \\
Few & 8 & 14.3 & 14.3 & 41.1 \\
Very & 33 & 58.9 & 58.9 & 100.0 \\
Total & 56 & 100.0 & 100.0 & \\
\hline
\end{tabular}

Source: own construction /calculation SPSS

In the question "The certification with QMS ISO 9001 results in increased performance" we have the following results:

\section{Chart 3.}

QMS \& Performance

\begin{tabular}{|ll|l|l|l|l|}
\hline & Frequency & Percent & Valid Percent & Cumulative Percent \\
\hline \multirow{2}{*}{ Valid } & None & 7 & & & \\
\hline & Few & 28 & 12.5 & 12.5 & 12.5 \\
& Very & 21 & 50.0 & 50.0 & 62.5 \\
\hline
\end{tabular}




\begin{tabular}{|l|l|l|l|}
\hline Total & 56 & 100.0 & 100.0
\end{tabular}

Source: own construction /calculation SPSS

In the question "Implementation of the QMS has improved the performance of human resource management" we have the following results:

\section{Chart 4.}

QMS \& Human resource

\begin{tabular}{|ll|l|l|l|l|}
\hline & & Frequency & Percent & Valid Percent & Cumulative Percent \\
\hline \multirow{4}{*}{ Valid } & None & 11 & 19.6 & 19.6 & 19.6 \\
& Few & 13 & 23.2 & 23.2 & 42.9 \\
& Very & 32 & 57.1 & 57.1 & 100.0 \\
& Total & 56 & 100.0 & 100.0 & \\
\hline
\end{tabular}

Source: own construction /calculation SPSS

In the question "The implementation of QMS has improved the operative performance" we have the following results:

\section{Chart 5.}

QMS \& operating performance

\begin{tabular}{|ll|l|l|l|l|}
\hline & & Frequency & Percent & Valid Percent & Cumulative Percent \\
\hline \multirow{4}{*}{ Valid } & None & 3 & 5.4 & 5.4 & 5.4 \\
& Few & 29 & 51.8 & 51.8 & 57.1 \\
& Very & 24 & 42.9 & 42.9 & 100.0 \\
& Total & 56 & 100.0 & 100.0 & \\
\hline
\end{tabular}

Source: own construction /calculations SPSS

\section{Empirical results}

The analysis of variables placed in the program were analyzed through descriptive empirical analysis presented below.

\section{Chart 6.}

\begin{tabular}{|c|c|c|c|c|c|c|}
\hline & & Standards ISO 9001 & Application of QMS & QMS -Performance & $\begin{array}{l}\text { QMS Human } \\
\text { resource }\end{array}$ & $\begin{array}{l}\text { QMS Operation } \\
\text { performance }\end{array}$ \\
\hline \multirow{7}{*}{$\begin{array}{l}\text { N } \\
\text { Mean } \\
\text { Median } \\
\text { Mode } \\
\text { Std. Deviation } \\
\text { Variance } \\
\text { Sum }\end{array}$} & Valid & 56 & 56 & 56 & 56 & 56 \\
\hline & Missing & 0 & 0 & 0 & 0 & o \\
\hline & & 38 & 1.32 & 1. 25 & 1. 38 & 1. 38 \\
\hline & & 00 & $\frac{2.00}{2}$ & $\mid \begin{array}{l}1.00 \\
1\end{array}$ & 2.00 & $\int_{1}^{1.00}$ \\
\hline & & 489 & 876 & 667 & 799 & 590 \\
\hline & & 239 & 768 & 445 & 639 & 348 \\
\hline & 25 & .00 & .00 & 1.00 & 1.00 & 1.00 \\
\hline \multirow[t]{2}{*}{ Percentiles } & 50 & .00 & 2. 00 & 1.00 & 2. 00 & 1.00 \\
\hline & 75 & 1.00 & 2. 00 & 2. 00 & 2. 00 & 2. 00 \\
\hline
\end{tabular}

Source: own construction /calculations SPSS 
Based on empirical descriptive analysis we have seen that businesses consider not important the use of the ISO 9001, based on average 38 , where at SPSS we made codification to answer all questions with indicative answers ${ }^{1}$, so the average approaching code 0 , which presents a not interest for ISO 9001 standard, this is also expressed through a narrow field of standard deviation of 489. Application of QMS from the businesses is seen to have little impact, based on an average of 1. 32 also this average that is similar with other variables shows that QMS does not bring effects enough for businesses, but large standard deviations of QMS is in the impact of human resources, the indicator of QMS that helps in managing human resources.

\section{Conclusions and recommendations}

Reflected above analysis reflects an element of reality to the development of businesses in Kosovo, seeing a lack of knowledge about international standards and a lack of knowledge of the application and implementation of the QMS.

Quality Services are related standards and capabilities. Supporting the creation of standards and support to education and support for supply for training are other aspects of tourism policy towards quality services. Orientation, informing and training the private sector to take reasonable investment decisions and to establish appropriate standards represent a policy approach to quality support. Also, qualitative services are related to industry and human resources. For setting targets for a competitive industry, it is necessary to create a framework for competitive industry and human resources.

I would emphasize the implementation of quality standards, because is not only the receipt of a certificate but to meet some criteria to join a new market or to increase the image. We have to understand that the implementation of quality standards bring great benefits to businesses, making it possible to reduce costs, increase productivity, becoming competitive in domestic and international markets of a number of positive chain reactions that come after. What attracts attention is that even though the system exists in the organizational culture in many tourist enterprises is not recognized as a quality management concept, but neither the concept of quality management system is not well known by employees. We are clear that quality is a mindset to be embraced, as it becomes an added value for the company. We should note that the tourism in Kosovo is having a non favorable position in comparison with other sectors.

The question is why is this happening? This happens for many reasons, but among the main reasons that businesses in the tourism sector which is found in our research is that they do not possess or do not have a fully consolidated systems of quality management. The other element found is that businesses and officials have a lack of knowledge in Quality Managment, in particular knowledge foreseen under the requirements of ISO 9001.

In order to change this is necessary that relevant state institutions and professional tourist organizations to:

Provide information and training on standards and appropriate actions in encouraging businesses to start with the application of international standards and their certification.

Establishment of responsibilities and functional structure for education and training in the tourism sector to create or adopt appropriate standards that constitute a policy approach to quality support.

\section{References}

[1] Beech, J. , Chadwick, S. (2006), The business of tourism management, Prentice Hall, Harlow

[2] Gilbert, G (1992), Quality improvement in a defense organization, Public Productivity and Management Review, Vol. 16 No. 1, pp. 65-75.

[3] Grzinic, Jasmina, Concepts of service quality measurement in hotel industry, p. 87, 2008

[4] International Standards Office, (2008), ISO 9001 - Quality management systems. Requirements. Geneva: ISO

1 0-None; 1-Little; 2- Much 
[5] Ishikawa, K. (1985), What is Total quality control? The Japanese way, Englewood Cliffs, NJ:Presentice Hall.

[6] ISO 10004:2012 Quality management - Customer satisfaction - Guidelines for mitoring and meansuring

[7] Nield, K- Kozak, M (1999), Quality certification in the hospitality industry: analyzing the benefits of ISO 9000. Cornell Hotel \& Restaurant Admnistration Quarterly, 40, 2. pp. 40-45

[8] Smith, A. K (1993) Total quality management in public sector, Quality Progress, June pp. 45-48 